\title{
DEMOCRACIA BRASILEIRA SOB PERIGO? UMA ANÁLISE À LUZ DOS ELEMENTOS DA JUSTIÇA DE TRANSIÇÃO
}

\author{
Emerson Francisco de Assis ${ }^{*}$
}

\begin{abstract}
Resumo
O objetivo deste trabalho é analisar a possibilidade de um golpe de Estado no regime democrático brasileiro instalado em 1985, considerando às inúmeras manifestações e preocupações neste sentido. A pesquisa adota a hipótese de que esta é uma possibilidade remota, apesar do baixo nível do processo de Justiça de Transição no Brasil, argumentando que elementos basilares da ordem democrática foram consolidados, por outro lado, há forte risco de deterioração da qualidade da democracia nacional. O trabalho usa o método hipotético-dedutivo com referencial teórico em Direitos Humanos, Ciência Política e História utilizando subsidiariamente, informações jornalísticas de veículos nacionais e internacionais confiáveis.
\end{abstract}

Palavras-chaves: Justiça de Transição. Democracia. Golpe de Estado. Direitos Humanos. Ditadura.

\section{IS IT THE BRAZILIAN DEMOCRACY UNDER DANGER? AN ANALYSIS OF THE ELEMENTS OF TRANSITIONAL JUSTICE}

\begin{abstract}
This paper's objective is to analyze the possibility of a coup d'état in the Brazilian democracy installed in 1985, considering the numerous manifestations and concerns in this regard. The search adopts the hypothesis that this is a remote possibility, despite the low level of the Transitional Justice process in Brazil, arguing that basic elements of the democracy were consolidated, by other hand, there is a strong risk of deterioration in the quality of democracy. The paper uses the hypothetical-deductive method with theoretical reference in Human Rights, Political Science, History and news from reliable national and international media.
\end{abstract}

Keywords: Transitional Justice. Democracy. Coup D'État. Human Rights. Dictatorship.

\section{Introdução}

Esta pesquisa visa discutir a possibilidade de ocorrência de um golpe de Estado em plena década de 2020 no Brasil. Como será abordado no decorrer do artigo, mesmo após mais de trinta anos do término da ditadura militar tem havido nos últimos tempos, discursos e manifestações pelo retorno do período autoritário no país, bem como pelo fechamento do Supremo Tribunal Federal (STF).

\footnotetext{
* Doutor em Direito e Mestre em Ciência Política pela Universidade Federal de Pernambuco (UFPE). Professor do Centro Universitário Tabosa da Almeida da Associação Caruaruense de Ensino Superior (ASCES-UNITA). Endereço: Rua Chico Mendes, 125, Térreo, Bairro Boa Vista, CEP: 55.038-280, Caruaru-PE. Email: obrejinheiro@hotmail.com.
} 
Para tanto, a análise será realizada a partir da discussão dos elementos, dimensões ou eixos do processo de Justiça de Transição realizado a partir do final do último período autocrático no Brasil.

Desta forma, a pesquisa levanta a hipótese de que é baixa a possibilidade de um golpe de Estado no Brasil, considerando que determinados elementos transicionais, especialmente à responsabilidade do Estado e dos agentes estatais, reformas institucionais entre outros que não eram existentes no contexto do golpe militar de 1964, a exemplo de mecanismos trazidos pela Constituição Federal de 1988, pela Convenção Americana de Direitos Humanos (Pacto de San José da Costa Rica - 1969) entre outros diplomas legais atualmente acolhidos no ordenamento jurídico brasileiro. Porém, pode existir uma situação de crise e desgaste para a democracia que geraria impactos não só políticos, mas sociais e até mesmo econômicos. É importante frisar que o trabalho não irá discutir fatores ligados à política nacional e internacional que influenciariam um eventual golpe e estejam desconectados de questões relativas à Justiça de Transição, por fugirem ao objeto deste trabalho.

O desenvolvimento do artigo está dividido em três partes. Na primeira é discutido o conceito de Justiça de Transição, seu histórico e elementos, dimensões ou eixos basilares. Na segunda parte será analisada a Justiça de Transição no Brasil especificamente e seus elementos, dimensões ou eixos. Por fim, na terceira e última parte do desenvolvimento é debatido o questionamento se de fato há possibilidade concreta de golpe de Estado no Brasil.

Para tanto, o trabalho fará uso do método hipotético-dedutivo, com referencial teórico na área de Direitos Humanos, Ciência Política e História no tocante à Justiça de Transição. Subsidiariamente, a pesquisa aborda informações obtidas de sites confiáveis de notícias de nível nacional e internacional, a exemplo da "Folha de São Paulo", "BBC News Brasil" e "El País Brasil".

\section{Justiça de Transição: conceito, breve histórico e elementos básicos}

Ruti Teitel $(2010$; 2011) criou o termo "Justiça de Transição" para designar uma concepção de justiça que esteja associada a tempos de mudanças políticas, marcados por 
respostas jurídicas que objetivam enfrentar os delitos cometidos em regimes ditatoriais do passado.

Louis Bickford (2004), por sua vez, observa que a Justiça de Transição se refere a um campo de atividade e pesquisa, focado em como as sociedades lidam com legados de autoritarismo e um passado de violação e abusos aos Direitos Humanos, atrocidades em massas ou outras formas de trauma social, a exemplo de genocídios ou guerras civis, com o intuito de construir um futuro mais pacífico e democrático.

O Conselho de Segurança das Nações Unidas (ONU), por meio de relatório de 23/08/2004, esmiúça um conceito de Justiça de Transição que engloba amplos processos e mecanismos utilizados na tentativa de uma sociedade enfrentar um passado de abusos dos Direitos Humanos em larga escala, objetivando alcançar responsabilização, justiça e reconciliação, incluindo tanto aparatos judiciais quanto extrajudiciais, com envolvimento internacional em diferentes níveis e responsabilização individual, indenizações, busca pela verdade, reformas institucionais, demissões de agentes do período ditatorial e uma combinação de variadas medidas (UNITED NATIONS, 2004).

De acordo com Tricia Olsen, Leigh Payne e Andrew Reiter (2013), a Justiça de Transição constitui um dos conjuntos mais relevantes de inovações da política internacional entre o final do século XX e começo do século XXI.

Do ponto vista do histórico da Justiça de Transição, Ruti Teitel (2011) alerta que esta implica em um tratamento não-linear de sua dimensão temporal, tendo geralmente avanços e retrocessos. Segundo a autora mencionada, as origens modernas da Justiça Transicional datam da Primeira Guerra Mundial, neste período, o objetivo geral era delimitar os parâmetros punitivos justificáveis para a comunidade internacional, em vista de uma guerra injusta.

Ao seu turno, Louis Bickford (2004) remarca as origens da Justiça de Transição para o cenário após a Segunda Guerra Mundial no âmbito europeu, especialmente no tocante ao julgamento dos criminosos nazistas pelo Tribunal Militar Internacional de Nuremberg, bem como os processos de desnazificação realizados na Alemanha naquela época. Glenda Mezarobba (2009) esclarece que neste cenário de pós-guerra, mecanismos da Justiça de Transição foram utilizados em países como Bélgica, França, Dinamarca, Países Baixos, Áustria e Hungria, que haviam sido invadidos ou ocupados pela Alemanha Nazista.

Contudo, Bickford (2004) ressalta que a Justiça de Transição só ganhou vulto nas duas últimas décadas do século XX, particularmente após os términos das ditaduras militares 
da Grécia (1975) e Argentina (1983). Este autor destaca que na região do Cone Sul da América Latina, inicialmente na Argentina e mais tarde atingindo Uruguai e Chile, a Justiça de Transição alcançou um patamar inédito no qual se ampliaram os limites do seu conceito e, o direito à memória e à verdade foi compreendido como algo irrenunciável. Esta concepção de Justiça Transição logo se ampliou para outras regiões do mundo fora da América Latina, como África do Sul, Polônia, Serra Leoa, Timor Leste etc.

Ruti Teitel (2011) também salienta um grande desenvolvimento na Justiça de Transição nos últimos 25 anos do século passado, período marcado pelo fim da Guerra Fria e queda da União Soviética com surgimento de processos de redemocratização no mundo inteiro, formando uma onda democrática transicional que alcançou inicialmente a América do Sul e, posteriormente, o Leste Europeu, a África e a América Central.

Após esta breve discussão conceitual e histórica, partindo para análise dos elementos que constituem a Justiça de Transição, Renan Quinalha (2013) alerta ser impossível estabelecer um rol taxativo destes elementos, que variam segundo a perspectiva adotada. Todavia, este autor também ressalva que existe um sentido mínimo e um traço comum entre as diversas análises, no qual as visões tradicionais identificam um conjunto de medidas e mecanismos recorrentes ou similares na Justiça de Transição. Para Quinalha (2013), as diferentes perspectivas adotadas pelos pesquisadores geralmente redundam em uma constelação composta de quatro ou cinco eixos centrais que comporiam a Justiça de Transição. Neste sentido, Quinalha (2013) defende que a Justiça Transicional abrange cinco eixos basilares: verdade, memória, justiça, reparação e reformas institucionais.

Glenda Mezarobba (2009) corroborando à análise de Quinalha (2013), delimita quatro elementos básicos para descrever a Justiça de Transição: direito à verdade, direito à justiça, direito à compensação e direito às instituições reorganizadas (reforma institucional). Se nota aqui o fato da última autora citada usar o termo "direito" ao invés de "eixos", "dimensões" ou "elementos", certamente no sentido de que tais elementos são realmente "direitos" de uma sociedade que atravessa um processo de redemocratização.

Por sua vez, Paulo Abrão (2012) resumiu a Justiça de Transição em quatro dimensões fundamentais, sendo elas: primeiramente, a reparação, fornecimento da verdade e construção da memória, em segundo lugar, a regularização da justiça, em terceiro, o reestabelecimento da igualdade perante a lei e a quarta e última, que se constitui na reforma das instituições perpetradoras de violações contra os direitos humanos. 
Por fim, de acordo com o Conselho de Segurança das Nações Unidas (2004), a Justiça de Transição é composta de "estratégias", divididas em cinco espécies: reparações, busca pela verdade, reforma institucional, depuração e demissão de agentes públicos. É salientado em Resolução do Conselho de Segurança que estas estratégias devem ser abordadas de forma holística e integrada.

Emerson de Assis (2017), por sua vez, faz uso do termo "dimensões" da Justiça de Transição, as quais seriam seis em sua análise: direito à memória e à verdade, responsabilização do Estado, responsabilização dos agentes estatais, reparação às vítimas e à sociedade, reformas institucionais e dimensão temporal. $\mathrm{O}$ último autor referenciado propõe a partir destes elementos, a criação de um indicador social para avaliar e comparar processos transicionais, denominado Índice de Avaliação de Processos Transicionais (IAPT), que será utilizado nesta pesquisa, por isso, os elementos transicionais na visão deste autor serão abaixo explicitados.

Para Assis (2017), o direito à memória e à verdade seria o conjunto de políticas públicas direcionadas para a preservação da memória e elucidação dos fatos que aconteceram durante a ditadura. Neste sentido, esta primeira dimensão comporta a criação de museus, espaços de memória, publicações e eventos científicos sobre o tema e, especialmente, a instalação de instituições como as comissões da verdade, destinadas a apurar fatos do passado autocrático.

Em relação à responsabilidade do Estado, esta seria a responsabilização estatal pelas ações do regime ditatorial passado, ocorre através de programas de pagamento de indenizações às vítimas da repressão autoritária e seus familiares, bem como, quando o Estado se assume publicamente e juridicamente como responsável pelas violações aos Direitos Humanos ocorridas durante a vigência autocrática (ASSIS, 2017).

Ao seu turno, através da responsabilidade dos agentes estatais existe a atribuição de responsabilidade civil, criminal e administrativa pessoal dos agentes que cometeram violações aos Direitos Humanos a serviço do regime ditatorial. Nesta dimensão ocorre ações como prisão, denúncia judicial e administrativa de integrantes do governo autocrático e agentes da repressão, como policiais, militares etc. Na dimensão/elemento anterior o foco era na atuação geral do Estado, nesta existe a atenção às ações individuais (ASSIS, 2017).

Na quarta dimensão da Justiça de Transição definida por Assis (2017), se verifica a reparação às vítimas e à sociedade que é realizada através do pagamento de indenizações às 
vítimas da repressão ditatorial e seus familiares, bem como a localização de corpos de oposicionista assassinados ou prestação de auxílio psicossocial direto. Este elemento transição é próximo da responsabilidade do Estado, porém, ela ocorre em face de casos concretos e situações específicas.

O próximo elemento a ser definido são as reformas institucionais que se configuram em ações de reforma legal e institucional do Estado, permitindo a consolidação da democracia. Estas reformas devem envolver principalmente os órgãos estatais que efetuaram violações diretas aos Direitos Humanos, como a polícias e Forças Armadas, mas atingindo também os Poderes Executivo, Legislativo e Judiciário, evitando que abusos do passado autoritário se repitam no presente democrático (ASSIS, 2017).

A dimensão temporal é um elemento no qual Emerson de Assis (2017) se difere dos demais pesquisadores da temática. Ela se dá por meio da avaliação do tempo gasto na evolução e desenvolvimento do processo transicional. Para este autor, um processo de transição ideal começaria o mais rápido após o regime ditatorial e se desenvolveria linearmente, sem sobressaltos. Assis (2017) ressalta que tal fato é concretamente raríssimo, sendo na verdade um tipo ideal, haja vista que a maioria dos processos de Justiça de Transição passam por avanços e retrocessos corriqueiramente.

No próximo tópico serão analisados estes elementos ou dimensões da Justiça de Transição aplicados ao caso do Brasil.

\section{A Justiça de Transição no Brasil e os seus Elementos, Dimensões ou Eixos Básicos}

Antes de adentrar nos elementos, dimensões ou eixos que compõe a Justiça de Transição no Brasil, é preciso abordar alguns aspectos sobre a ditadura militar brasileira. Thomas Skidmore (1988) observa que este regime autocrático durou 21 anos, entre 1964 e 1985, se iniciando através de um golpe de Estado que depôs o presidente João Goulart e teve o apoio de amplos setores da sociedade nacional e internacional, da mídia, da Igreja Católica e de setores conservadores da classe média e empresariado, além dos Estados Unidos, cabendo a liderança deste movimento aos militares brasileiros. 
Anthony Pereira (2010) ressalta que entre as ditaturas militares por eles estudadas, surgidas na América Latina no contexto da Guerra Fria, nas décadas de 1960 e 1970, o regime autoritário brasileiro foi o mais longo e firmemente enraizado.

Como resultado de mais de vinte anos de regime ditatorial, a Comissão Nacional da Verdade (CNV) registrou pelo menos 434 mortes ou desaparecimentos de pessoas, individualmente identificadas, sendo 191 mortes, 210 desaparecimentos sem localização de paradeiro e 33 desaparecimentos com identificação dos corpos. Todos são vítimas diretas da ação repressiva do Estado brasileiro e seus agentes, entretanto, o próprio relatório da CNV reconhece que estes números podem ser maiores, na medida em que uma parte considerável das ações ditatoriais não foram devidamente esclarecidas, principalmente se levada em considerações às vítimas entre os camponeses e os povos indígenas (BRASIL, 2014).

O processo de Justiça de Transição no Brasil foi iniciado ainda no decorrer do regime autocrático, através da aprovação da Lei de Anistia (Lei Federal nº 6.683 de 1979), (ABRÃO, 2012). Várias instituições que inicialmente haviam apoiado a instauração da ditadura militar como a Ordem dos Advogados do Brasil (OAB) e a Igreja Católica passaram a pressionar pela volta à normalidade constitucional e legal a partir do final da década de 1970 (PEREIRA, 2010). Além disso, como destaca Paulo Abrão (2012), o movimento pela anistia gerou grande mobilização popular, permitindo que manifestações e passeatas voltassem às ruas, solicitando uma anistia ampla, geral e irrestrita.

Todavia, a proposta de anistia ampla defendida pela sociedade civil foi derrotada, vigorando a proposta restringida pelo governo ditatorial, que não abrangia os chamados “crimes de sangue", que envolviam homicídios, por exemplo (ABRÃO, 2012). Anthony Pereira (2010) analisa que neste período houve tanto concessões à oposição, quanto afirmações autoritárias do governo ditatorial, pois a Lei de Anistia, por um lado, protegeu os agentes estatais que cometeram violações aos Direitos Humanos, mas, simultaneamente libertou a maior parte dos presos políticos e permitiu o retorno dos brasileiros asilados políticos no exterior.

É preciso compreender, conforme Paulo Abrão (2012), que no Brasil ocorreu uma transição controlada para democracia, onde os militares somente aceitaram um processo de abertura que fosse em sua avaliação, lenta, gradual e segura. Para tanto, fizeram uma aliança com a oposição, formada por uma elite política e burocrática que ascendeu durante o próprio regime autocrático. Segundo Thomas Skidmore (1988) esta abertura gradual havia sido 
anunciada desde o início do governo do general Ernesto Geisel em 1974, penúltimo presidente ditatorial, sendo que uma transição gradual e controlada foi planejada por este e seu ministro, o general Golbery do Couto e Silva.

Por outro lado, Skidmore (1988) explica que os líderes da oposição à ditadura sabiam que só poderiam passar a um regime aberto com a cooperação dos militares.

Paulo Abrão (2012) afirma que este forte controle da ditadura militar sobre a democracia insurgente é simbolicamente iniciado com a Lei de Anistia de 1979 e se estendeu até 1985, quando as forças políticas de suporte ao regime autocrático impediram a aprovação de uma emenda constitucional para realização de eleições diretas para presidente, a despeito da forte pressão popular consubstanciada no movimento Diretas-Já.

No período final da ditadura, segundo Anthony Pereira (2010) o regime ficou sujeito à fortes críticas da sociedade, sendo a mais notável trazida pelo relatório "Brasil: Nunca Mais”, elaborado pela Arquidiocese de São Paulo, então coordenada pelo cardeal Dom Paulo Evaristo Arns, que documentou as atrocidades cometidas pelo governo ditatorial e alcançou a posição de "best-seller".

Naquele mesmo ano de 1985, no qual o referido livro foi publicado, durante o governo Sarney, primeiro presidente civil efetivamente empossado após a ditadura, a Emenda Constitucional $n^{\circ}$ 26/1985 convocou a Assembleia Constituinte que gestou a Constituição Federal de 1988 e confirmou expressamente a validade da Lei de Anistia de 1979 (SABADELL; DIMOULIS, 2014).

De acordo com Ana Lúcia Sabadell e Dimitri Dimoulis (2014), a partir da confirmação constitucional da anistia política em 1988, esta problemática passou a ser questionada somente em meios ligados à esquerda política, grupos formados por vítimas da repressão autocrática e seus familiares, bem como organizações não-governamentais (ONG's) de proteção aos Direitos Humanos, se tornando assim, um assunto distante do interesse da sociedade em geral.

Após este período, medidas importantes na área de Justiça de Transição só vieram a acontecer a partir do governo Fernando Henrique Cardoso, empossado em 1995, na qualidade de primeiro opositor autêntico da ditadura de 1964 a chegar à presidência da República. Por iniciativa de seu governo, o Congresso Nacional aprovou a criação de uma comissão com objetivo de identificar e localizar mortos e desaparecidos por atos do regime autocrático (PEREIRA, 2010). Também foi instalada no final do governo Cardoso a partir de 2001, 
através de medida provisória convertida na Lei $\mathrm{n}^{\circ}$ 10.559/2002, a Comissão de Anistia que visava reconhecer a responsabilidade do Estado por ato de exceção para além de morte e desaparecimentos, através do pagamento de indenizações ou atos de reparação (ABRÃO, 2012).

Pouco depois, durante a presidência de Luiz Inácio Lula da Silva, no ano de 2005, o governo federal trouxe a público através do Arquivo Nacional, documentação dos órgãos repressivos da ditadura, facilitando o acesso dos pesquisadores, das vítimas e seus familiares, embora tenha sido notada a ausência ou extravio de muitos documentos importantes (SABADELL; DIMOULIS, 2014).

Logo em seguida, em 2006, através de iniciativa de órgãos do Ministério Público e de vítimas e familiares, o ajuizamento de ações no âmbito civil ou criminal visando a responsabilização pessoal direta de agentes da ditadura que cometeram violações aos Direitos Humanos (SABADELL; DIMOULIS, 2014).

Em geral, se observa que a primeira década do século XXI trouxe marcos importantes para a Justiça de Transição no Brasil. Neste sentido, no ano de 2008, o Conselho Federal da OAB ingressou com a Arguição de Descumprimento de Preceito Fundamental (ADPF) $n^{\circ} 153$ no Supremo Tribunal Federal (STF), pugnando a inconstitucionalidade da Lei de Anistia de 1979, feito julgado improcedente dois anos depois, em 2010 (SABADELL; DIMOULIS, 2014).

Segundo Paulo Abrão (2012), a decisão do STF em reconhecer a validade e constitucionalidade da Lei de Anistia, permitiu estabelecer uma continuidade direta e objetiva entre o sistema jurídico da ditadura e o regime democrático, impedindo a investigação de ilícitos penais cometido pelo Estado e seus agentes durante a vigência autocrática.

Para o último autor citado, a tese da anistia recíproca, argumento que em suma justificou a decisão consolidada na $\operatorname{ADPF} n^{\circ} 153$, acabou preponderando na visão dos julgadores dos ministros do STF (ABRÃO, 2012). Neste sentido, esclarece Bruno Galindo que no STF foi corroborado um entendimento de que a Lei de Anistia perdoou os "dois lados", quer seja, tantos os crimes dos guerrilheiros que aderiram à luta armada, quanto dos agentes da repressão autocrática.

Emerson de Assis (2013) argumenta que três fatores influenciaram na decisão do julgamento comentado, primeiramente, o conservadorismo político do Poder Judiciário brasileiro. Em segundo lugar, as alianças políticas do então Executivo Federal que mesmo 
sendo ocupado pelo Partido dos Trabalhadores (PT), se fundamentava em uma coalização composta por políticos e grupos com amplas raízes na ditadura. E por último, o posicionamento contrário dos principais veículos da mídia nacional.

No ano de 2010 também houve o julgamento do Caso Gomes Lund e Outros (Guerrilha do Araguaia) em face do Brasil na Corte Interamericana de Direitos Humanos em San José, Costa Rica, visando a responsabilização internacional do Estado brasileiro por oposicionistas mortos pela repressão militar na década de 1970, no vale do rio Araguaia (SABADELL; DIMOULIS, 2014). Nesta ação, o referido tribunal condenou o Brasil internacionalmente por tais fatos e ainda criticou o julgamento da ADPF $\mathrm{n}^{\circ} 153$ no STF, declarando que a vigência da Lei de Anistia no país é incompatível com a Convenção Americana sobre Direitos Humanos (Pacto de San José da Costa Rica) ao impedir a punição de graves violações aos Direitos Humanos ocorridas no período autocrático, consideradas imprescritíveis nesta convenção (ASSIS, 2013).

Pouco tempo após esta decisão favorável da Corte Interamericana de Direitos Humanos foi instalada em 2012 a Comissão Nacional da Verdade (CNV), no governo de Dilma Rousseff em cerimônia no Palácio do Planalto, contando com participação dos expresidentes José Sarney, Fernando Collor, Fernando Henrique Cardoso e Luiz Lula da Silva. Esta comissão visou apurar os atos de exceção, abusos aos Direitos Humanos e identificar vítimas e agentes repressores, referentes à ditadura militar instalada no Brasil a partir de 1964 (BRASIL, 2014).

Todavia, a CNV e suas congêneres instaladas a nível estadual e municipal em todo o Brasil, não produziram os frutos desejados. Como observam Ana Lúcia Sabadell e Dimitri Dimoulis (2014) desde o reconhecimento da constitucionalidade da Lei de Anistia pelo STF em 2010, qualquer eventual discussão sobre a punição dos agentes da ditadura passou a ser considerada como "revanchismo". Os autores consideram isto uma opção política de Justiça de Transição pelo "olvido", isto é, através do "esquecimento".

Como lembra Bruno Galindo (2012), um passado autoritário não pode ser superado pelo esquecimento de crimes de lesa humanidade ocorridos no período ditatorial. A superação do autoritarismo, segundo o autor, implica em exorcizar os seus fantasmas, prevenindo que situações semelhantes ocorram no futuro.

Diante do contexto apresentado, partindo para análise dos elementos básicos da Justiça de Transição brasileiros na avaliação de Emerson de Assis (2017), nos termos do 
Índice de Avaliação de Processos Transicionais (IAPT), se verifica claramente que o processo transicional no Brasil alcançou um baixo nível, obtendo o escore de 0,458 , entre um valor mínimo de " 0 " e máximo de " 1 ".

Por exemplo, no tocante ao direito à memória e à verdade se verifica um baixo desempenho do processo transicional brasileiro, afinal, como já exposto, primeiramente, a CNV foi criada quase 30 anos após o final da ditadura. Também existem poucos espaços destinados à memória do período autocrático, além do fato que, amplos setores da sociedade e da vida política no Brasil fazem apologia do regime ditatorial até hoje (ASSIS, 2017).

Em relação ao elemento responsabilidade do Estado, este alcançou patamar médio para Assis (2017), tendo em vista que Estado brasileiro criou programas de pagamento de indenizações às vítimas da repressão e seus familiares, bem como, várias comissões para apurar violações aos Direitos Humanos na ditadura. Por outro lado, seus esforços não foram considerados suficientes e o Brasil acabou condenado internacionalmente na Corte Interamericana de Direitos Humanos no Caso Guerrilha do Araguaia, como já mencionado. O governo federal assumiu publicamente sua responsabilidade pelos crimes de lesa humanidade cometidos naquela época, mas setores como as Forças Armadas e policiais nunca o fizeram.

Também logrou desempenho médio na visão do último autor citado, a responsabilidade dos agentes estatais brasileiros na ditadura. Pois, como exposto, o STF reconheceu a constitucionalidade da Lei de Anistia que impede a persecução penal de tais agentes, todavia, foi possível a responsabilização individual administrativa via CNV e a civil no Poder Judiciário (ASSIS, 2017). Recentemente, em junho de 2021 ocorreu a primeira condenação criminal de um agente repressor da ditadura por delitos cometidos neste período, o delegado Carlos Alberto Augusto na 9 ${ }^{a}$ Vara Criminal Federal de São Paulo, um fato inédito no processo transicional brasileiro e que pode gerar precedentes importantes no futuro (VENDRUSCOLO, 2021).

No tocante ao elemento/dimensão de reparação às vítimas e sociedade, esta foi o único no qual para Assis (2017) se alcançou um patamar elevado, considerando que o Estado brasileiro efetivamente pagou indenização pecuniárias às vítimas da repressão autocráticas e/ou seus familiares, além de ter efetuado reconhecimento oficial individualizado de tais ações lesivas aos Direitos Humanos.

No quinto elemento a ser analisado, quer seja, as reformas institucionais, o Brasil obteve uma avaliação mediana para Assis (2017). De acordo com este autor, muitas reformas 
institucionais foram realizadas no Brasil, especialmente trazidas na Constituição Federal de 1988 que consolidaram a democracia, a separação, a independência e as garantias dos três Poderes: Executivo, Legislativo e Judiciário, além do Ministério Público, que passou a ser um órgão com autonomia e muito mais força. Porém, em regra geral, as Forças Armadas e polícias continuam seguindo diretrizes e formas de organização herdadas do regime autoritário e são resistentes às mudanças.

Por fim, em relação a sua dimensão temporal, Emerson de Assis (2017) indica que o processo transicional brasileiro obteve um baixo desempenho, haja vista sua morosidade, como por exemplo, na instalação da Comissão Nacional da Verdade quase três décadas após o término da ditadura. Além disso, processos judiciais e administrativos movidos por vítimas da repressão e seus familiares se arrastaram por décadas e o Brasil somente reconheceu sua responsabilidade internacional pelos abusos cometidos no período autocrático, após sofrer condenação na Corte Interamericana de Direitos Humanos em 2010.

O nível baixo atingido pelo processo de Justiça de Transição do Brasil fica ainda mais patente quando seu IAPT $(0,458)$ é comparado com os de outras nações da América Latina que passaram por regimes similares no mesmo contexto histórico de Guerra Fria, sendo o escore do Chile de 0,791 e da Argentina, 0,916, por exemplo, países que tiveram um desempenho muito superior neste aspecto (ASSIS, 2017).

Porém, o baixo desempenho do processo de Justiça de Transição no Brasil implica em haver uma maior possibilidade de golpe de Estado no país? Esta questão será respondida no próximo tópico.

\section{Golpe de Estado no Brasil na década de 2020: uma possibilidade concreta?}

O Instituto Datafolha em pesquisa de opinião, apurou que aproximadamente $50 \%$ dos brasileiros acreditam que existem a possibilidade real do presidente Jair Bolsonaro tentar um 
golpe de Estado. A pesquisa foi realizada entre os dias 13 a 15/09/2021, em 190 municípios de todo o Brasil, inquerindo 3.667 pessoas e com margem de erro de dois pontos percentuais para mais ou menos (GIELOW, 2021).

O Datafolha constatou também que $51 \%$ dos entrevistados temem que o Brasil volte a ser uma ditadura, sendo este o percentual mais alto já alcançado em pesquisas elaboradas pelo instituto em questão (GIELOW, 2021).

Esta pesquisa de opinião do Datafolha ocorreu uma semana após a maior tensão institucional entre o governo Bolsonaro e outros Poderes, particularmente o Judiciário. No dia 07/09/2021, o presidente da República liderou milhares de manifestantes às ruas, fez críticas contundentes a alguns ministros do STF, pregou desobediência à Suprema Corte, bem como caminhoneiros por ele convocados, ameaçaram invadir o prédio do referido tribunal e fazer uma greve para paralisar o Brasil (GIELOW, 2021). Houve ainda manifestações pedindo o fechamento do STF, do Congresso Nacional e intervenção militar (BARIFOUSE; SCHREIBER, 2021). Em discurso para os manifestantes, Bolsonaro, inclusive, mencionou que em seu embate como o STF, poderia " [...] jogar fora das quatro linhas da Constituição [...].” (GIELOW, 2021).

Além disso, vale ressaltar que desde o período em que foi deputado federal, o presidente Jair Bolsonaro sempre foi conhecido por fazer apologia do regime autocrático implantado em 1964. No exercício da presidência houve uma moderação de tom, porém, comemorações do golpe militar mencionado foram realizadas no âmbito das Forças Armadas e Ministério da Defesa (GIELOW, 2021).

A mobilização de policiais militares e membros das Forças Armadas em prol das manifestações de 07/09/2021 a favor de Bolsonaro, também levaram a temores de motins e golpes não só neste período, mas durante as futuras eleições de 2022 (OLIVEIRA, 2021).

Porém, será que todas estas manifestações poderiam ensejar realmente um golpe de Estado no Brasil em pleno século XXI, mais de trinta anos após o final da última ditadura?

A presente pesquisa não discutirá eventuais conjunturas políticas de nível nacional ou internacional em sua análise, somente os fatores que estejam efetivamente ligados ao processo de Justiça de Transição realizado no Brasil.

Neste sentido, de antemão é necessário afastar a hipótese simplista de que um processo de Justiça de Transição que alcançou um baixo desempenho, como o do Brasil, implique necessariamente numa grande possibilidade de golpe de Estado. Afinal, seria preciso 
considerar os elementos componentes da Justiça Transicional individualmente, pois em algumas destas dimensões, inclusive, o Brasil alcançou índice mediano ou elevado.

Avaliando primeiramente o elemento do direito à memória e à verdade, que Assis (2017) indica haver baixo desempenho do processo de Justiça de Transição no Brasil. Um dado importante levantado pela pesquisa do Instituto Datafolha mencionada foi que $70 \%$ das pessoas ouvidas entendem que democracia é o melhor regime para o Brasil e somente $9 \%$ indicam ser a ditadura uma melhor opção (GIELOW, 2021). Este é um dado positivo em relação a consolidação desta dimensão transicional, pois indica que a ideia da democracia e rejeição da ditadura está sedimentada na ampla maioria da população.

Por outro lado, a participação de milhares de pessoas em atos que pregam o fechamento de determinados Poderes da República, como o Judiciário, com apoio de amplos setores da sociedade como caminhoneiros e profissionais de segurança pública, não deixa de ser preocupante. Aliás, a própria eleição de políticos que fazem apologia da ditadura pretérita é um paradoxo da democracia brasileira, que certamente denota uma dimensão de memória e verdade de baixo desempenho.

Em relação às dimensões da responsabilidade do Estado e dos agentes estatais, como já visto, estas alcançaram nível mediano na avaliação de Assis (2017). Neste sentido, em artigo de opinião no jornal "Folha de São Paulo", no final do mês de agosto de 2021, ensejado pela organização das manifestações de 07/09, o ministro do STF Ricardo Lewandowski (2021) afirma que uma aventura golpista no Brasil poderia levar à responsabilização estatal ou individual dos agentes envolvidos, a nível nacional ou até mesmo internacional.

De acordo com Lewandowski (2021), ações que caracterizam um golpe de Estado são passíveis de punição nos termos da Constituição Federal, do Código Penal e do Código Penal Militar, não havendo, em casos de envolvimento de militares, excludente de culpabilidade acolhida pelo art. 142 da Constituição Federal, que permite a utilização das Forças Armadas para garantia da segurança e ordem nacional.

O ministro em questão também lembrou que o Brasil ratificou o Estatuto de Roma do Tribunal Penal Internacional, o qual sujeitaria eventuais ações de golpistas à reponsabilidade criminal nesta corte internacional (LEWANDOWSKI, 2021). As palavras de Lewandowski (2021) parecem claramente querer servir de alerta para a alta possibilidade de responsabilização daqueles que tentarem ou perpetrarem um golpe de Estado no Brasil de hoje, inclusive, o ministro alerta expressamente: "Como se vê, pode ser alto o preço a pagar 
por aqueles que se dispõem a transpassar o Rubicão." (LEWANDOWSKI, 2021). Vale salientar, que estes mecanismos de responsabilização, especialmente os internacionais, não eram disponíveis por ocasião do golpe militar de 1964.

Quanto ao elemento de reparação às vítimas e a sociedade, aliás, o único no qual o Brasil obteve patamar elevado no IAPT criado por Assis (2017). Este não teria por si só o condão de atenuar ou impedir ações golpistas, mas funcionaria como um precedente importante dentro de um processo transicional de redemocratização após o eventual golpe de Estado.

No tocante à dimensão de reformas institucionais, no qual o Brasil logrou nível mediano de acordo Assis (2017), no contexto discutido, ela se ligaria à responsabilização estatal e de seus agentes, pois estes mecanismos somente surgiram graças às reformas institucionais. Na perspectiva da Justiça de Transição brasileira, o principal instrumento legal de reformas institucionais foi a Constituição Federal de 1988. Nela, estão asseguradas o Estado Democrático de Direito (Art. $1^{\circ}$ ), a independência e harmonia entre os Poderes Executivo, Legislativo e Judiciário (art. $2^{\circ}$ ), apontado como crime inafiançável e imprescritível a ação de grupos civis e militares contra a democracia (art. $5^{\circ}$, XLIV), isto entre outros inúmeros dispositivos da Carta Magna de 1988 que garantem a democracia brasileira em geral (BRASIL, 1988).

Não há dúvidas que existem muitas normas legais nacionais ou internacionais que resguardam à democracia brasileira, especialmente a Constituição Federal, contudo, estes mecanismos funcionariam em suma situação concreta de golpe de Estado?

Esta é uma pergunta sobre a qual não se pode dar uma resposta efetiva, por motivos óbvios: seria necessário que um evento de ruptura ocorresse para testá-los na prática. Contudo a reação dos Poderes Judiciário e Legislativo após as manifestações de 07/09/2021, podem ser um indicativo.

Um dia após os discursos e protestos a favor do presidente Jair Bolsonaro, os presidentes da Câmara de Deputados e do STF fizeram críticas públicas as suas atitudes. Sendo que o pronunciamento mais duro veio do ministro Luiz Fux, presidente da Suprema Corte que alertou expressamente a Bolsonaro que descumprir decisões do referido tribunal poderia configurar crimes de responsabilidade, o tornando alvo de processo de impeachment (BARIFOUSE; SCHREIBER, 2021). 
A reação do deputado federal Artur Lira, do Partido Progressistas de Alagoas (PPAL), presidente da Câmara de Deputados e aliado do governo federal, foi menos incisiva: pediu um fim da escalada de tensão entre os Poderes da República e o término de bravatas em redes sociais (BARIFOUSE; SCHREIBER, 2021).

Após estas reações, somadas à repercussão negativa do discurso presidencial na política em geral e no mercado, com alta do dólar e queda da bolsa de valores, dois dias depois das manifestações, o presidente Bolsonaro divulgou uma carta em tom apaziguador, declarando que não teve intenção de agredir quaisquer Poderes (PASSARINHO, 2021). Segundo o referido documento, que foi mediado e redigido pelo ex-presidente Michel Temer, Bolsonaro declarou que "[...] minhas palavras, por vezes contundentes, decorreram do calor do momento e dos embates que sempre visaram o bem comum [...].” (PASSARINHO, 2021). A recepção dos demais Poderes à carta de desculpas de Bolsonaro foi considerada mista, de acordo com a avaliação da jornalista Nathalia Passarinho (2021), sendo encarada por muitos com um recuo estratégico.

Do ponto de vista da dimensão reformas institucionais no processo de Justiça de Transição brasileiro, se percebe claramente que a Constituição Federal de 1988 não conseguiu apenas criar, mas consolidar instituições, no caso do Poder Legislativo e particularmente do Judiciário, com capacidade e iniciativa suficiente para responder às ameaças oriundas do Poder Executivo e fazer este pedir desculpas publicamente e recuar, mesmo que de forma estratégica, de sua postura ofensiva.

Por outro lado, o apoio dos militares, seja das polícias ou Forças Armadas às manifestações é algo preocupante, pois como salienta Assis (2017), o setor de segurança pública é exatamente uma das maiores lacunas nas reformas institucionais promovidas pelo processo transicional brasileiro.

Por fim, o último elemento transicional a ser discutido, isto é, a dimensão temporal, não traz perspectivas positivas para esta discussão, na medida em que o Brasil enfrentou um processo de Justiça de Transição moroso, marcado pelo esquecimento do passado autocrático.

Todavia, fazendo um balanço entre a análise dos diversos elementos que compõe a Justiça de Transição no Brasil não há forte indicativa da possibilidade de golpe de Estado no Brasil. Claro, esta análise desconsidera fatores de ordem política nacional e internacional que estejam desconectados das discussões e das dimensões transicionais. 
Embora o processo de Justiça de Transição no Brasil tenha alcançado um baixo desempenho, nele existem elementos que conferem uma maior robustez à democracia e que certamente não estavam presentes em 1964, por ocasião do último golpe militar, como já aludido.

Porém, ainda que seja baixa a possibilidade de um golpe de Estado no Brasil nos termos do aqui ocorrido na Guerra Fria, ela não é nula: existem políticos e grupos organizados que se manifestam publicamente neste sentido. Este é um paradoxo perigoso para a democracia brasileira e que pode até não a derrubar, mas um desgaste com repercussões políticas, sociais e econômicas já está amplamente visível. A própria discussão desta possibilidade de golpe em plena década de 2020, mesmo remota, por si só, já é um sintoma de falha na democracia brasileira e em seu processo de Justiça de Transição.

\section{Considerações Finais}

Pegando o gancho do último parágrafo do tópico passado, discutir se é possível um golpe de Estado no Brasil, em plena década de 2020, mais de trinta anos após o término de uma ditadura militar, por si só, já é um fato alarmante, ainda mais quando motivado por discursos e manifestações contrárias a harmonia, a independência dos Poderes da República e fazendo apologia ao autoritarismo pretérito.

Entretanto, o processo de Justiça de Transição realizado no Brasil, apesar de suas grandes lacunas e falhas, e, de uma forma geral, ser considerando um processo de baixo nível, trouxe e consolidou elementos que não haviam por ocasião do golpe de 1964, quer sejam, especialmente os mecanismos legais trazidos pela Constituição Federal de 1988 e tratados internacionais como a Convenção Americana sobre Direitos Humanos e o Estatuto do Tribunal Penal Internacional (TPI). Este fato turbinou elementos basilares da Justiça de Transição, particularmente a responsabilização estatal e de seus agentes, bem como as reformas institucionais.

As instituições nacionais, com destaque para o Poder Judiciário mostram capacidade de reação quando provocadas e este certamente é um fator positivo para democracia brasileira. 
Embora haja uma minoria importante e ruidosa que defenda a ditadura e o autoritarismo, a grande maioria da população brasileira é a favor do regime democrático, quer seja, 70\% dos entrevistados pelo Instituto Datafolha (2021), como mencionado no decorrer do artigo. Este também é um fator extremamente positivo para sociedade brasileira.

Em suma três fatores principais corroborariam a hipótese de ser baixa a possibilidade de um golpe de Estado no Brasil na década de 2020, considerando exclusivamente os aspectos relativos à Justiça de Transição: Primeiramente, existe um maior apoio da população brasileira à democracia, a qual se liga ao elemento do direito à memória e à verdade, que levariam à lembrança do passado autoritário e rejeição de governos ditatoriais.

Em segundo lugar, há mecanismos legais e institucionais consolidados a nível nacional e internacional entre os quais a Carta Magna e os tratados mencionados, além de que, os Poderes estatais possuem independência e autonomia suficiente para responder às ameaças contra o Estado Democrático de Direito. Este plano se comunica ao elemento transicional de reformas institucionais.

No terceiro e último lugar, os agentes e instituições, a exemplos e policiais de Forças Armadas envolvidos eventualmente em algum golpe de Estado poderiam responder criminal, civil e administrativamente no âmbito nacional, junto ao Poder Legislativo e Judiciário e internacionalmente na Corte Interamericana de Direitos Humanos ou no Tribunal Penal Internacional como salientado pelo ministro Ricardo Lewandowski.

Por fim, este trabalho traz um apelo sobre a importância da manutenção e aprofundamento do processo de Justiça de Transição no Brasil, para que ameaças à democracia nacional sejam cada vez mais uma possibilidade remota.

\section{Referências}

ABRÃO, Paulo. Direito à Verdade e à Justiça na Transição Política Brasileira. In: ; GENRO, Tarso. (orgs.) Os Direitos da Transição e a Democracia no Brasil: estudos sobre justiça de transição e teoria da democracia. Belo Horizonte: Fórum, 2012, pp. 59-80.

ASSIS, Emerson Francisco de. Índice de Avaliação de Processos Transicionais (IAPT): uma proposta para maior objetividade na análise de processos de justiça de transição. In: ENCONTRO ANUAL DA ANPOCS, 41., 2017, Caxambu-MG. Anais Eletrônicos... Caxambu: ANPOCS, 2017. Disponível em: http://www.anpocs.com/index.php/papers-40encontro-2/spg-4/spg09-4. Acesso em 05 jan. 2018. 
Influências Políticas na Ineficácia da Sentença do Caso Gomes Lund (Guerrilha do Araguaia): A Corte Interamericana de Direitos Humanos em face da República Federativa do Brasil. In: PFLUG, Samantha Ribeiro Meyer; ANTUNES, Álvaro Gonçalves; ANDREUCCI, Evandro Fabiani Capano (coords.). Memória, Verdade e Justiça de Transição.

Florianópolis: FUNJAB, 2013, pp. 333-360. Disponível em:

http://www.publicadireito.com.br/artigos/?cod=ed2357bbbd318d58. Acesso em: 27 mar. 2014.

BARIFOUSE, Rafael; SCHREIBER, Mariana. Em reação a Bolsonaro, Fux fala em crime de responsabilidade, mas Lira não cita impeachment. BBC News Brasil. 08 set. 2021.

Disponível em: https://www.bbc.com/portuguese/brasil-58495283. Acesso em: 24 set. 2021.

BICKFORD, Louis. Transitional Justice. In: SHELTON, Dinah L. (org.). The Encyclopedia of Genocide and Crimes Against Humanity. Detroit: Macmillan Reference USA, 2004, v. 3, pp. 1045-1047.

BRASIL. Constituição Federal de 1988. Disponível em: http://www.planalto.gov.br/ccivil_03/constituicao/constituicao.htm. Acesso em: 24 set. 2021.

\section{Comissão Nacional da Verdade (CNV). Relatório da Comissão Nacional da}

Verdade. Brasília: CNV, 2014, v. 1. Disponível em:

http://www.cnv.gov.br/index.php/outrosdestaques/574-conheca-e-acesse-o-relatorio-final-dacnv. Acesso em: 15 jan. 2015.

GALINDO, Bruno. Justiça de Transição na América do Sul: possíveis lições da Argentina e do Chile ao processo constitucional de transição no Brasil. In: FEITOSA, Enoque et al. $\mathbf{O}$ Judiciário e o Discurso dos Direitos Humanos. Recife: Universitária da UFPE, 2012, v. 2, pp. 197-240.

GIELOW, Igor. Datafolha: Metade dos brasileiros diz acreditar que Bolsonaro pode dar golpe. Folha de São Paulo. 18 set. 2021. Disponível em:

https://www1.folha.uol.com.br/poder/2021/09/datafolha-metade-dos-brasileiros-diz-acreditarque-bolsonaro-pode-dar-golpe.shtml. Acesso em: 19 set. 2021.

LEWANDOWSKI, Ricardo. Intervenção armada: crime inafiançável e imprescritível. Folha de São Paulo. 28 ago. 2021. Disponível em:

https://www1.folha.uol.com.br/opiniao/2021/08/intervencao-armada-crime-inafiancavel-eimprescritivel.shtml. Acesso em: 29 ago. 2021.

MEZAROBBA, Glenda. O Que é Justiça de Transição? Uma análise do conceito a partir do caso brasileiro. In: SOARES, Virgínia Prado; KISHI, Sandra Akemi Shimada (orgs.).

Memória e Verdade: a justiça de transição no Estado Democrático brasileiro. Belo Horizonte: Fórum, 2009, pp. 37-53.

OLIVEIRA, Joana. Mobilização de PMs para ato pró-Bolsonaro em 7 de setembro eleva receios de motim eleitoral em 2022. El País Brasil. 25 ago. 2021. Disponível em: 
https://brasil.elpais.com/brasil/2021-08-25/mobilizacao-de-pms-para-ato-pro-bolsonaro-em-7de-setembro-eleva-receios-de-motim-eleitoral-em-2022.html. Acesso em: 23 set. 2021.

OLSEN, Tricia; PAYNE, Leigh; REITER, Andrew. Superando a Impunidade na América Latina. In: SILVA FILHO, José Carlos Moreira da; ABRÃO, Paulo; TORELLY, Marcelo (coords.). Justiça de Transição nas Américas: olhares interdisciplinares, fundamentos e padrões de efetivação. Belo Horizonte: Fórum, 2013, pp. 227-266.

PASSARINHO, Nathalia. Os bastidores do impacto no Supremo de carta 'apaziguadora' de Bolsonaro. BBC News Brasil. 10 set. 2021. Disponível em: https://www.bbc.com/portuguese/brasil-58523377. Acesso em: 24 set. 2021.

PEREIRA, Anthony W. Ditadura e Repressão: o autoritarismo e o estado de direito no Brasil, no Chile e na Argentina. São Paulo: Paz e Terra, 2010.

QUINALHA, Renan Honório. Justiça de Transição: contornos do conceito. São Paulo: Outras Expressões; Dobra, 2013.

SABADELL, Ana Lucia; DIMOULIS, Dimitri. Anistias Políticas: considerações de história e política do direito. In: SABADELL, Ana Lucia; SIMON, Jan-Michel; DIMOULIS, Dimitri (orgs.). Justiça de Transição: das anistias às comissões de verdade. São Paulo: Revista dos Tribunais, 2014, pp. 249-278.

SKIDMORE, Thomas E. Brasil: de Castelo e Tancredo, 1964-1985. Rio de Janeiro: Paz e Terra, 1988.

TEITEL, Ruti G. Genealogia da Justiça Transicional. In: REÁTEGUI, Félix (org.). Justiça de Transição: manual para a América Latina. Nova York: Centro Internacional para Justiça de Transição, 2011, pp. 135-170.

Global Transitional Justice. New York: New York Law School, 2010. Disponível em: https://www.gmu.edu/centers/globalstudies/publications/hjd/hjd_wp_8.pdf. Acesso em 11 jan. 2017.

UNITED NATIONS. Security Council. The Rule of Law and Transitional Justice in Conflict and Post-Conflict Societies: report of the General Secretary n.S/2004/616. 23 ago. 2004. Disponível em: http://archive.ipu.org/splz-e/unga07/law.pdf. Acesso em 07 jan. 2017.

VENDRUSCOLO, Stephanie. Pela primeira vez, Justiça condena penalmente repressor da ditadura brasileira e abre precedente histórico. El País Brasil. 21 jun. 2021. Disponível em: https://brasil.elpais.com/brasil/2021-06-21/pela-primeira-vez-justica-federal-condenapenalmente-repressor-da-ditadura-brasileira-e-abre-precedente-historico.html. Acesso em: 24 set. 2021. 